\title{
SOBRE A EDUCAÇÃO DE JOVENS E ADULTOS - EJA: A EDUCAÇÃO E O TRABALHO PARA ALÉM DA EXCLUSÃO
}

\author{
ODINEI INACIO TEIXEIRA ${ }^{1}$ \\ Programa de Pós-graduação em Linguística \\ Universidade Federal de São Carlos \\ Rodovia Washington Luís, km 235 - São Carlos, SP - Brasil. CEP: 13565-905
}

odineiteixeira@gmail.com

\begin{abstract}
Resumo. O movimento analítico dos discursos sobre a Educação de Jovens e Adultos (EJA) representa a importância do respeito do poder público ao direito de aprender, à inclusão social e à cidadania. A Sequência Discursiva em análise é constituída por discursos do Ministério da Educação (MEC) para a EJA. Importa destacar que a memória mostra que há representações imaginárias institucionais do MEC por meio de suas políticas públicas. Por outro lado, há os sujeitos que se configuram enquanto alunos da EJA, com as suas expectativas acerca da escolarização regular, e a sua situação familiar e social, marcadas pela necessidade de trabalhar, na infância, com a interrupção de estudos. É essa realidade que perpassa o discurso institucional e dos sujeitos, e faz emergir a formação discursiva da exclusão. Palavras-chave: Educação de Jovens e Adultos; Ministério da Educação; Análise de Discurso; memória; implícitos.
\end{abstract}

\begin{abstract}
The analytical movement of discourses about Youth and Adult Education (EJA) represents the importance of the public authorities' respect for the right to learn, social inclusion and citizenship. The Discursive Sequence in analysis consists of discourses from the Ministry of Education (MEC) to EJA. It is important to highlight that the memory shows that there are institutional imaginary representations of the MEC through its public politics. On the other hand, there are the subjects that configure themselves as students of EJA, with their expectations about regular schooling, and their family and social situation, marked by the need to work in childhood with the interruption of studies. It is this reality that permeates the institutional and subjects' discourse, and gives rise to the discursive formation of exclusion.
\end{abstract}

Keywords: Education for Young People and Adults; Ministry of Education; Discourse Analysis; memory; implicit.

\footnotetext{
${ }^{1}$ Doutor em Linguística pela UFSCar. Professor Universitário no curso de Pedagogia no CESTUPI - Centro de Ensino Superior de Tupi Paulista/Faculdade de Tupi Paulista. Assessor de Direção Escolar da E.M. Presidente Castello Branco, no município de Santa Mercedes-SP.
} 


\section{INTRODUÇÃO}

Esse trabalho é parte constituinte de nossa pesquisa de Doutorado desenvolvida no Programa de Pós-graduação em Linguística - PPGL, na Universidade Federal de São Carlos - UFSCar.

A Educação de Jovens e Adultos (EJA) representa um importante segmento da Educação Básica no Brasil, pois possibilita aos educandos que não puderam se escolarizar na idade regular, a escolarização formal, mesmo num espaço de tempo reduzido. E é a partir desse movimento que se dá a relevância social da escolarização para esses sujeitos, pois propicia o direito de aprender, a inclusão social e a cidadania.

A constituição da Sequência Discursiva analisada recai sobre os discursos do Ministério da Educação (MEC) para a EJA, especialmente, aqueles veiculados por meio do seu portal na internet ${ }^{2}$, na sua secretaria destinada às políticas públicas educacionais destinadas à EJA, a SECADI - Secretaria de Educação Continuada, Alfabetização, Diversidade e Inclusão. Selecionamos os seguintes textos para compreender o discurso ou as Formações Discursivas (FD) presentes no discurso do MEC: as Propostas Curriculares ${ }^{3}$ para a área de Língua Portuguesa, destinada aos educandos do $1^{\circ}$ ao $5^{\circ}$ Ano do Ensino Fundamental - $1^{\circ}$ Segmento da EJA, os Cadernos Trabalhando com a EJA $A^{4}$ e vídeo da Campanha Publicitária de $2016^{5}$. Ainda em relação a esse material, sobre a sua relevância em relação aos educadores, dada a posição de que "uma proposta curricular deve ser um subsídio para educadores desenvolverem planos de ensino adequados aos seus contextos" (BRASIL, 2001, p. 14), compreender os efeitos de sentidos nele circulados permite-nos interpretar melhor a posição do MEC em relação à EJA.

A constituição da sequência discursiva do nosso trabalho emerge em meio às diversas manifestações do MEC. Assim, ao tratar das questões teóricas relacionadas às materialidades discursivas, Pêcheux (2016) destaca que "surge precisamente daquilo que, entre a história, a língua e o inconsciente, resulta como heterogeneidade irredutível: um remoer de falas ouvidas, relatadas ou transcritas, uma profusão de escritos mencionando falas e outros escritos" (p. 23-24).

Ao considerarmos que os alunos são os principais sujeitos do processo de ensino e de aprendizagem, destacamos que os alunos da EJA, por suas peculiaridades relacionadas à escolarização fora da idade regular e por serem sujeitos jovens e adultos que possuem responsabilidades quanto ao trabalho e à família, acabam diante de uma realidade escolar, cujo ensino é diretamente influenciado pelas representações do MEC em relação a esses sujeitos, e essas representações, que muitas vezes podem ser incoerentes com a realidade desses educandos, interferem na oferta de um ensino público que atenda às necessidades desses sujeitos.

\footnotetext{
${ }^{2}$ Disponível em http://portal.mec.gov.br/. Acesso em 14/04/2016.

3 Disponível em http://portal.mec.gov.br/secad/arquivos/pdf/eja/propostacurricular/primeirosegmento/propostacurricular.p df. Acesso em 20/10/2016.

${ }^{4}$ Disponível em https://www.youtube.com/watch?v=srIUUb4M7io. Acesso em 17/10/2016.

${ }^{5}$ Disponível em https://www.youtube.com/watch?v=srIUUb4M7io. Acesso em 14/04/2016.
} 
Deste modo, por meio do dispositivo teórico da Análise de Discurso (AD) de vertente pecheutiana, pretende-se compreender as diversas representações do MEC em relação à EJA e que se manifestam nas Propostas Curriculares que orientam a estruturação e o desenvolvimento de projetos de ensino. Pretende-se compreender também, por meio da leitura e análise de campanha publicitária, o posicionamento desse Ministério. Assim, o discurso político do MEC para a EJA constitui subsídios para o desenvolvimento de projetos de ensino que acometem diretamente esse público, seja pela efetivação ou pela não efetivação dessas políticas públicas educacionais e suas respectivas consequências sociais.

O caráter político do discurso do MEC permite a emergência de sentidos relacionados ao desenvolvimento de políticas públicas educacionais ao público jovem e adulto, na modalidade da EJA. E nesse sentido, sendo esse Ministério a maior autoridade no país, no que tange ao desenvolvimento e à regulamentação de políticas públicas educacionais, é de sua responsabilidade a criação de programas que, de modo efetivo, contribuam com a escolarização desses sujeitos que não puderam frequentar a escola ou que não puderam permanecer na escola na idade regular, dada a importância que a sociedade atribui à escolaridade enquanto instrumento para a inclusão social do sujeito.

As investigações acerca do discurso político do MEC ocorrem devido ao fato de considerarmos a relevância da presença da ideologia, das formações discursivas e dos interdiscursos que circulam, sobretudo, nesse discurso oficial em relação à EJA. Tais formulações constituem-se enquanto sentidos que significam na elaboração e no desenvolvimento das políticas públicas da EJA, e no imaginário institucional do MEC e dos sujeitos a respeito dessas políticas públicas educacionais. Deste modo, Pêcheux (1988) mostra que "as ideologias têm uma história própria, uma vez que elas têm uma existência histórica e concreta" (PÊCHEUX, 1988, p. 151), e essa interpelação ideológica constitui sentidos e história que, profundamente, marcam a EJA e os sujeitos que se escolarizam ou que buscam a escolarização por meio dela.

\section{A MEMÓRIA E O FUNCIONAMENTO DOS IMPLÍ́CITOS}

Conforme Achard (2007), a partir do posicionamento sobre a análise do discurso e sobre o estatuto dos implícitos, as abordagens sobre a memória estão situadas em posições delicadas. Assim, Achard mostra que há risco da interpretação psicologista dos implícitos, pois a "estruturação do discursivo vai constituir a materialidade de uma certa memória social" (ACHARD, 2007, p. 11). A materialidade não remete à retórica das explicações que são da ordem do indizível, do indescritível ou do inconsciente coletivo, até mesmo a expressão 'memória social' é constituída por um valor que não possibilita analisá-la.

Achard (2007) mostra que há algumas hipóteses relacionadas ao funcionamento formal no discurso, à circulação dos discursos. Estas relações permitem aos sujeitos o afastamento de interpretações psicológicas da memória em relação ao que já foi ouvido sobre algo.

A representação do funcionamento dos implícitos mostra que estes são sintagmas cujo conteúdo é memorizado e a sua explicitação é formada por uma paráfrase constituída por esta memorização que funciona sob a forma de um consenso. Deste modo, os 
pressupostos e os consensos sobre os implícitos constituem uma representação.

Ao tratar sobre os manuais escolares,

\begin{abstract}
eles constituem uma vulgata ${ }^{6}$ em relação a textos mais 'elaborados', o exame dos manuais concretos e sua confrontação permite colocar em evidência não somente que eles estão sujeitos à crítica, apresentam variações consideráveis de um a outro, são insatisfatórios para o que se espera deles, mas ainda que é ao nível dos propósitos implícitos supostos por eles que eles chegam a constituir a dita vulgata. Em suma, eles constituem a ilustração do fato de que, enquanto um registro discursivo supõe uma vulgata para funcionar, a tentativa de esclarecimento, de explicitação dessa vulgata, jamais 'contém' o que seria necessário para funcionar na retomada, e constitui na melhor das habilidades uma primeira retomada da vulgata. (ACHARD, 2007, p. 12)
\end{abstract}

Em relação à abordagem discursiva, Achard (2007) mostra que o implícito trabalha sobre um imaginário que o representa como memorizado, pois cada discurso, ao propô-lo, apela à sua reconstrução restrita "no vazio de que eles respeitem formas que permitam sua inserção por paráfrase. Mas jamais podemos provar ou supor que esse implícito (re)construído tenha existido em algum lugar como discurso autônomo" (ACHARD, 2007, p. 13). "De outro modo, o passado, mesmo que realmente memorizado, só pode trabalhar mediando as reformulações que permitem reenquadrá-lo no discurso concreto face ao qual nos encontramos" (p. 14).

Achard (2007) ao considerar a necessidade de análise, cujo funcionamento linguístico comporta um registro discursivo, trata o problema do sentido de uma palavra. Assim, admite como "hipótese lexicológica que o que caracteriza a palavra é a sua unidade, sua identidade a si mesma, que permite reconhecê-la em seus diferentes contextos" (p. 14). A coocorrência das palavras leva a novos contextos que contribuem à construção do sentido. Contudo, para atribuir sentido a essa unidade é necessário que se admitam as repetições tomadas por uma regularidade, ou seja, uma hipótese do analista. "Em termos linguísticos, isso corresponde a constatar que o corpus nunca é suficiente para fundar a gramática, e que a regularização repousa sobre um jogo de força [...] que pode designar o sentido como limite" (p. 15).

Ainda em relação à memória, trataremos a seguir sobre a visão discursiva e a sua relação com a memória apoiada nos postulados de Pêcheux (1988).

\title{
A MEMÓRIA: ESPAÇO PARA DESLOCAMENTOS, RETOMADAS E CONFLITOS
}

Pêcheux (2007) introduz a temática sobre a memória a partir de condições constituídas por mecanismos e por processos, e mostra que sobre estas condições, há um acontecimento histórico, um elemento histórico descontínuo e exterior que pode "se inscrever na continuidade interna, no espaço potencial de coerência próprio a uma

\footnotetext{
${ }^{6}$ Trata-se de "a versão mais difundida ou mais aceita como autêntica de um texto" (HOUAISS, 2015).
} 
memória" (PÊCHEUX, 2007, p. 50).

Memória deve ser entendida aqui não no sentido diretamente psicologista da 'memória individual', mas nos sentidos entrecruzados da memória mítica, da memória social inscrita em práticas, e da memória construída do historiador. O risco evocado de uma vizinhança flexível de mundos paralelos se deve de fato à diversidade das condições supostas com essa inscrição: é a dificuldade - com a qual é preciso um dia se confrontar - de um campo de pesquisas que vai da referência explícita e produtiva à linguística, até tudo o que toca as disciplinas de interpretação: logo a ordem da língua e da discursividade, a da 'linguagem', a da 'significância' [...], do simbólico e da simbolização... (PÊCHEUX, 2007, p. 50)

Nesse sentido, há uma tensão contraditória no processo de inscrição do acontecimento no espaço da memória sob uma dupla forma-limite que desempenhou o papel de ponto de referência: "o acontecimento que escapa à inscrição, que não chega a se inscrever; o acontecimento que é absorvido na memória, como se não tivesse ocorrido" (PÊCHEUX, 2007, p. 50).

Ao tratar sobre a imagem e a sua relação com os fatos do discurso enquanto inscrição material em uma memória discursiva, Pêcheux destaca que:

Essa negociação entre o choque de um acontecimento histórico singular e o dispositivo complexo de uma memória poderia bem, com efeito, colocar em jogo a nível crucial uma passagem do visível ao nomeado, na qual a imagem seria um operador de memória social, comportando no interior dela mesma um programa de leitura, um percurso escrito discursivamente em outro lugar: tocamos aqui o efeito de repetição e de reconhecimento que faz da imagem como que a recitação de um mito. $\mathrm{Na}$ transparência de sua compreensão, a imagem mostraria como ela se lê, quer dizer, como ela funciona enquanto diagrama, esquema ou trajeto enumerativo. (PÊCHEUX, 2007, p. 51)

Pêcheux (2007), ao tratar sobre a memória discursiva, mostra que frente a um texto que será lido, são reestabelecidos implícitos que, ou seja, elementos pré-construídos, citados, relatados, discursos transversos, cuja leitura necessita a condição do legível em relação ao próprio legível. Deste modo, a regularização discursiva forma a lei da série do legível, pois é sempre suscetível ruir sobre o acontecimento discursivo novo e interfere na memória:

a memória tende a absorver o acontecimento, como uma série matemática prolonga-se conjeturando o termo seguinte em vista do começo da série, mas o acontecimento discursivo, provocando interrupção, pode desmanchar essa 'regularização' e produzir retrospectivamente, uma outra série sob a primeira, desmascarar o aparecimento de uma nova série que não estava constituída enquanto tal e que é assim o produto do acontecimento; o acontecimento, no caso, desloca e desregula os implícitos associados ao sistema de regularização anterior. (PÊCHEUX, 2007, p. 52)

Conforme Pêcheux, há um jogo de força na memória em relação ao choque do 
acontecimento, pois esse jogo busca manter uma regularização pré-existente com os implícitos por ela veiculados e confronta-os com a estabilização parafrástica que integra o acontecimento, absorvendo-o e dissolvendo-o. Entretanto, esse jogo é de uma desregulação, pois também desestabiliza a rede dos implícitos. Assim, a repetição tornase um efeito material constituído por comutações e variações que assegura, principalmente, no nível da frase escrita, "a estabilidade de uma vulgata parafrástica produzida por recorrência, quer dizer, por repetição literal dessa identidade material" (PÊCHEUX, 2007, p. 53).

A opacidade marca o momento em que os implícitos não são mais reconstrutíveis, a análise do discurso passa a se distanciar das evidências da proposição, da frase e da estabilidade parafrástica, e, também, questiona os efeitos materiais de montagens de sequências, sem buscar a sua significação ou as suas condições implícitas de interpretação.

Pêcheux afirma que uma memória não pode ser concebida como algo pleno, com bordas formadas por transcendentais históricos, com conteúdo homogêneo e acumulado como em um reservatório, mas sim, como "um espaço móvel de divisões, de disjunções, de deslocamentos e de retomadas, de conflitos e de retomadas, de conflitos de regularização... Um espaço de desdobramentos, réplicas polêmicas e contra discursos" (PÊCHEUX, 2007, p. 56).

Ao propormos o movimento analítico que também se alicerça nas concepções de memória, destacamos as diversas representações imaginárias que são constituídas nos diversos meios que estabelecem a conjuntura da EJA, pois há o imaginário institucional do MEC que se propaga por meio do desenvolvimento de políticas públicas aplicadas ao público da EJA, o olhar desse Ministério frente à sociedade não-escolarizada e que necessita do ensino formal. Nessa esteira, também há os sujeitos que se configuram enquanto alunos da EJA, com as suas expectativas acerca da escolarização regular, e a sua situação familiar e social.

Assim, as diversas concepções e representações se renovam em conformidade com o dinamismo da própria sociedade e é por meio do fio discursivo, e das construções interpretativas que podemos compreender a diversidade que se instaura no panorama da EJA, tanto sob o viés institucional representado pelo MEC, quanto pelo viés social representado pelos educandos. Apesar das atualizações, o arquivo e a memória representam a própria historicização do sistema educativo brasileiro e a agravante situação social excludente que assola, desde o início da colonização do país, principalmente, os sujeitos com pouca ou nenhuma escolaridade.

Sobre a atualização da memória e a recorrente falta de escolarização no país, passaremos à análise de sequência discursiva no próximo item.

\section{A MEMÓRIA E OS DISCURSOS SOBRE A EJA: A NÃO ESCOLARIZAÇÃO}

As Propostas Curriculares e a Campanha Publicitária de 2016 da EJA constituem subsídios que se articulam com os sistemas de ensino e orientam a realização de políticas 
educacionais e projetos educacionais para o público jovem e adulto.

Os discursos que constituem essa sequência discursiva caracterizam o público atendido pela EJA, e, também, as especificidades em relação à transposição dos conteúdos das orientações curriculares para os currículos oficiais desenvolvidos nas escolas. Nesse sentido, recorremos aos recortes da Proposta Curricular e à Campanha Publicitária de 2016.

\section{SEQUÊNCIA DISCURSIVA 1 - Sobre o público da EJA}

No Brasil, há mais de 35 milhões de pessoas maiores de catorze anos que não completaram quatro anos de escolaridade. Esse grande contingente constitui o público potencial dos programas de educação de jovens e adultos correspondentes ao primeiro segmento do ensino fundamental. Além dos 20 milhões identificados como analfabetos pelo Censo de 1991, estão incluídas nesse contingente, pessoas que dominam tão precariamente a leitura e a escrita que ficam impedidas de utilizar eficazmente essas habilidades para continuar aprendendo, para acessar informações essenciais a uma inserção eficiente e autônoma em muitas das dimensões que caracterizam as sociedades contemporâneas. (BRASIL, 2001, p. 35)

Figura 24 - Captura de tela: Campanha Publicitária - Educação de Jovens e Adultos.

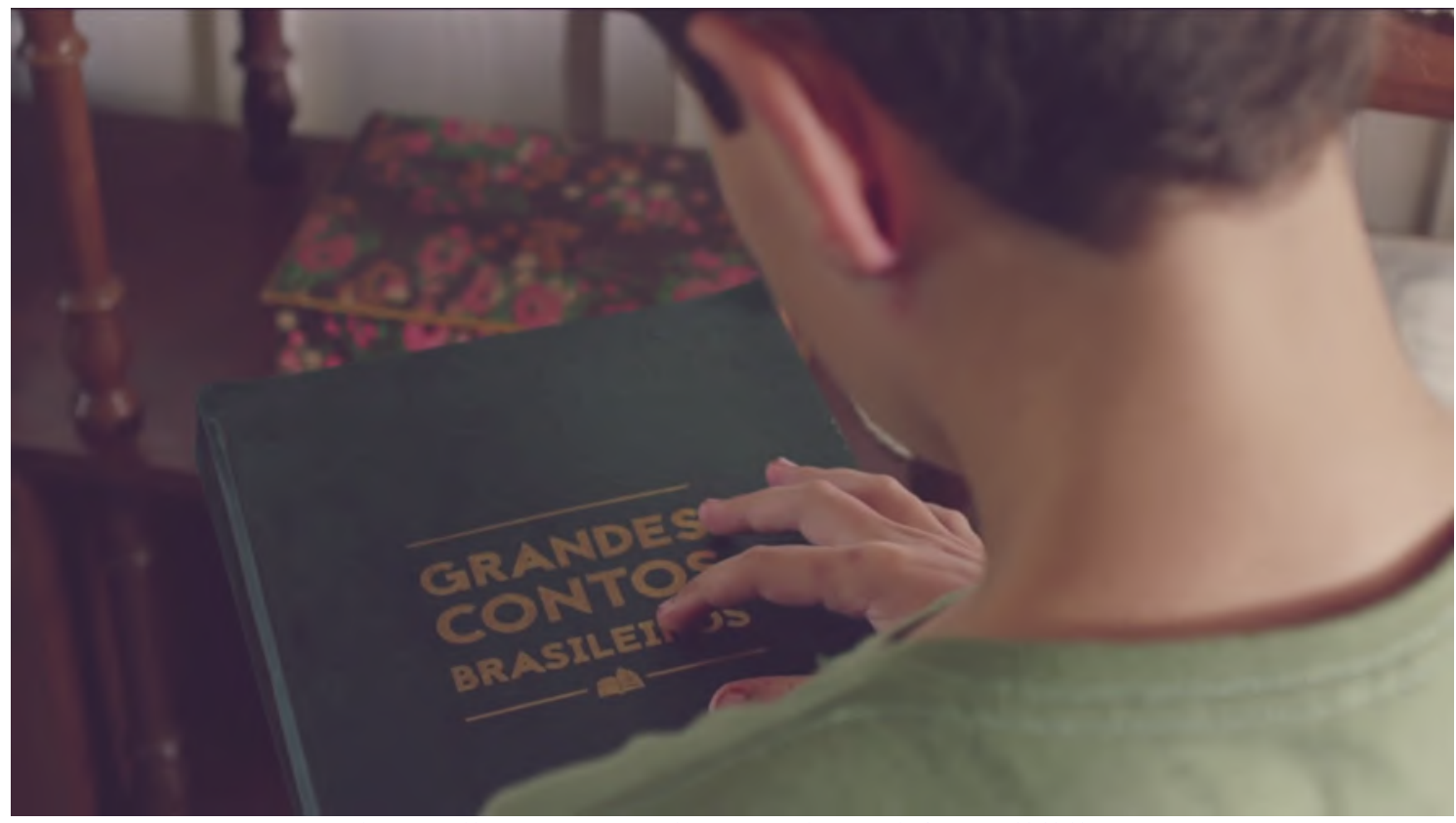

Fonte: https://www.youtube.com/watch?v=srIUUb4M7io.

Nessa sequência discursiva (1), o fragmento textual da Proposta é constituído pela realidade brasileira em relação ao cenário do "público potencial" dos programas educacionais da EJA. O Governo, enquanto enunciador, reconhece essa problemática social e demarca a gravidade da situação educacional do país por meio das expressões "35 milhões de pessoas maiores de catorze anos" e "grande contingente". Há, nesse 
sentido, o emprego do discurso matemático representado pela quantidade numérica "35 milhões" e o emprego do advérbio "grande" para acentuar a proporção numérica estabelecida pelo numeral e salientar a preocupação do enunciador com a gravidade e com a dimensão social ocasionada por essa realidade que representa algo amplo e constituinte da sociedade brasileira.

Trata-se de um número bastante elevado de sujeitos que possuem baixa ou nenhuma escolaridade ao compararmos esses dados com o número de habitantes do país, conforme o censo de 2010, realizado pelo IBGE (Instituto Brasileiro de Geografia e Estatística), que é de 190.732.694 de pessoas.

Os dados apresentados pela Proposta e que são referentes à baixa escolaridade e que se atualizam por meio de pesquisas do IBGE, remetem a uma memória histórica, pois remete a uma realidade que tem se tornado recorrente na conjuntura brasileira, representando, não somente uma época, mas sim, uma série de épocas.

A partir da análise das formas de inscrição da historicidade (de uma formação social em uma dada conjuntura) na linguagem, torna-se possível entrever os processos discursivos que atuam na perpetuação e cristalização de determinados sentidos em detrimento de outros, ou seja, processos discursivos que tecem e homogeneízam a memória de uma época. (MARIANI, 1993, p. 41)

Ainda nesse fragmento textual, o enunciador volta a empregar o discurso matemático por meio do numeral "20 milhões" para representar a sua perplexidade em relação à situação social brasileira no que tange à leitura e à escrita, pois o número empregado salienta que muitos sujeitos, apesar de conhecerem o sistema de leitura e de escrita, não conseguem utilizá-lo em atividades diárias, tampouco para o prosseguimento dos estudos. Ou seja, trata-se de uma inoperância do sistema de ensino cuja função básica de ensinar o sistema de leitura e de escrita da linguagem acaba sendo lacunar, o que acarreta o futuro insucesso escolar de muitos sujeitos que constituem o "público potencial" da EJA.

A problemática instaurada pela baixa escolarização acaba sendo caracterizada como algo a se perder de vista, pois no fragmento em análise dessa sequência discursiva, há o emprego da expressão "muitas das dimensões que caracterizam as sociedades contemporâneas" para representar a impossibilidade do acesso à progressão de possibilidade de novas aprendizagens que só podem ser concretizadas por meio do conhecimento e do uso proficiente do sistema de escrita.

Assim, há a manifestação do não dizer, pois é inerente à contemporaneidade a necessidade de construção de novos saberes que, frequentemente, só podem ocorrer por meio do conhecimento do sistema de leitura e de escrita, assim como a apropriação de informações básicas que são comunicadas aos cidadãos por meio da escrita. Nesse sentido, o não dizer rompe com o estável e mostra as consequências negativas do desconhecimento do sistema de escrita e de leitura, pois aquilo que é escrito e não decodificado, consequentemente, colocará em suspenso a interpretação, a produção de novos sentidos e de novos saberes, pois:

a língua fluida é a que pode ser observada e reconhecida quando focalizamos os processos discursivos, através da história da 
constituição de formas e sentidos, tomando os textos como unidades (significativas) de análise, no contexto de sua produção.

Se a língua imaginária é a que os analistas fixam na sua sistematização, a língua fluida é que não pode ser contida no arcabouço dos sistemas e fórmulas.

É essa língua que estamos colocando como ponto de referência para pensar a questão do empréstimo [...]. Língua na qual convivem processos muito diferentes e cuja história é feita de fartura e movimento. (ORLANDI, 1988, p. 34)

A língua fluida é referência para vincularmos às noções de certo e de errado, que por sua vez, são constituintes do espaço escolar, pois há a supremacia do que é estabelecido como certo em detrimento do que é considerado como errado. Entretanto, apesar de ser recorrente esse posicionamento tanto no espaço escolar, quanto no espaço educacional, a língua é constituída por diferentes processos que representam movimentos constitutivos e significativos à própria língua.

Britto (2008) afirma que o ensino centrado em determinada teoria gramatical, a sua respectiva metalinguagem e a valorização de uma modalidade linguística no ensino determinaram à escola o abandono do texto, que é fundamental no exercício da língua. A reinserção do texto na sala de aula faz com que a língua seja pensada em suas condições efetivas de uso. Deste modo, o ensino de gramática está relacionado ao fato de se pensar a língua em conformidade com a forma como ela é exercitada e avaliada em sociedade. Conforme a perspectiva do certo em detrimento do errado, Britto entende que ocorre um processo onde há certo apagamento da língua, pois há a centralidade no normativismo. Sabemos que na perspectiva da $A D$, junto com Possenti (2011), há uma ruptura da $A D$ com a Pragmática.

Sobre a ruptura, Possenti mostra que a AD não trabalha sob a perspectiva do

[...] acréscimo de uma pitada histórica, cultural, ideológica, psicológica ou psicanalítica ao que diz a linguística, em seus diversos compartimentos. Não é simplesmente a fonoestilística, a conotação, a sintaxe voltada para o falante, a semântica a que se acrescenta o tempo do contexto, ou o texto como efeito de um processo. (POSSENTI, 2011, p. 357)

Assim, a AD trabalhará cada tema sob a perspectiva do rompimento com o que a linguística faz com cada um deles, baseando-se em transformações.

Nesse sentido, há o distanciamento entre o enunciador, representado pelas Propostas Curriculares e o público-alvo, os alunos da EJA, pois é sabido pelo próprio poder público que, na maioria das vezes, a passagem pela escola foi fracassada, cabendo, agora, a criação e o desenvolvimento de políticas públicas educacionais, mais precisamente, de um sistema de ensino regular que atenda tanto às expectativas quanto às necessidades do público jovem e adulto que retorna à escola.

Ao instaurar o distanciamento entre as Propostas e os alunos da EJA, faz-se necessário que o poder público realize certo deslocamento em relação às orientações das Propostas, para que estas sejam, efetivamente, alicerçadas nas práticas escolares, especificamente, na sala de aula. Ou seja, essa perspectiva refere-se à transposição, ao modo como o 
professor recebe essa orientação curricular. Em conformidade com tal movimento, Rojo, ao tratar da importância do deslocamento dos Parâmetros Curriculares Nacionais (PCN) para a sala de aula, sugere a "transposição dos PCN às práticas de sala de aula" (2006, p. 28), com o intuito de ouvir e fazer ouvir os verdadeiros atores do processo educativo, professores e alunos. É em conformidade com esse movimento que Rojo (2006) destaca que tais Documentos devem estabelecer um diálogo com as experiências educativas já existentes neste nível.

A transposição dos Referenciais à prática está relacionada à importância de se ouvir os verdadeiros envolvidos no processo de ensino e de aprendizagem, ou seja, professores e alunos, pois esses sujeitos podem explicitar quais práticas pedagógicas podem ser consideradas como exitosas ou não exitosas. Assim, o fato de serem atuantes no processo de ensino e de aprendizagem, poderá contribuir, de modo positivo, com o poder público no que tange à posterior elaboração ou reelaboração de conteúdos, procedimentos metodológicos e avaliativos coerentes com a realidade escolar e com as peculiaridades vivenciadas pela EJA, e que constituirão o discurso dos Referenciais Curriculares.

Ao verificarmos o recorte de imagem do filme acerca da Campanha Publicitária, há a atualização discursiva do que é proclamado no interior das Propostas Curriculares em relação ao público jovem e adulto que não pôde frequentar a escola devido à necessidade de trabalhar, pois a Campanha Publicitária se inscreve em uma conjuntura onde a imagem acaba por operacionalizar a memória social da cultura brasileira, uma vez que:

[...] com efeito, se a imagem define posições de leitor abstrato que o espectador concreto é convidado a vir ocupar a fim de poder dar sentido ao que ele tem sob os olhos, isso vai permitir criar, de uma certa maneira, uma comunidade - um acordo - de olhares: tudo se passa então como se a imagem colocasse no horizonte de sua percepção a presença de outros espectadores possíveis tendo o mesmo ponto de vista. [...] a reconstrução de um acontecimento passado necessita, para se tornar lembrança, da existência de pontos de vista compartilhados pelos membros da comunidade e de noções que lhes são comuns; assim, a imagem por poder operar o acordo dos olhares, apresentaria a capacidade de conferir ao quadro da história a força da lembrança. Ela seria nesse momento o registro da relação intersubjetiva e social. (DAVALLON, 2007, p. 31, grifos do autor)

Ao demarcar na Campanha Publicitária a imagem das mãos de um garoto, cujas unhas estão sujas de terra devido à necessidade de trabalhar e auxiliar o seu pai que é pedreiro, ocorre a forte presença da memória social, que por ser tão frequente e incisiva no Brasil, acaba sendo fortemente representada pelo discurso oficial presente nas Propostas e na Campanha Publicitária.

Este fato também remete à memória histórica, pois a sequência de fatos demarcados na Campanha Publicitária representam uma realidade não muito distante dos dias atuais, pois na conjuntura brasileira, sempre foi comum o trabalho de crianças e de adolescentes, principalmente, os filhos mais velhos que ajudavam os seus pais no trabalho e no sustento de toda a família, inclusive, dos irmãos mais novos. Dessa forma,

[...] o papel da memória histórica seria, então, o de fixar um sentido sobre os demais (também possíveis) em uma dada conjuntura. Ou ainda, 
vista deste ângulo, à memória estaria reservado o espaço da organização, da linearidade entre passado, presente e futuro, isto é, a manutenção de uma coerência interna da diacronia de uma formação social. (MARIANI, 1993, p. 41)

$\mathrm{Na}$ Campanha publicitária, há o rompimento com a memória histórica, quando o homem conclui os seus estudos e muda de profissão, deixando de ser operário, passando a ter um cargo melhor na construção civil.

Assim, quando o garoto passa os dedos sobre o título da obra com escrita materializada por letras douradas em uma capa de livro com a cor verde, cujo título é Grandes contos brasileiros, há, não somente a representação de que o garoto sente as consequências negativas de não frequentar a escola e, por conseguinte, não saber ler os contos brasileiros que constituem essa obra literária, mas também, a atualização da memória brasileira acerca das crianças e jovens que não frequentaram a escola na idade certa, cujas representações estão presentes e atualizadas na memória dos cidadãos brasileiros por meio de imagens, mas que, por sua vez, também constituem um "conto brasileiro".

É esse mesmo conto que ultrapassa as representações de imagens sociais, se atualiza na publicidade do MEC e, por fim, acaba sendo escrito e inscrito no espaço destinado à ficção, mas que ao ser lido e interpretado, remete às consequências negativas que marcam, estigmatizam e excluem os sujeitos que não puderam frequentar a escola na idade apropriada.

No que concerne à representação da realidade educacional brasileira por meio do título da obra Grandes contos brasileiros, há a abertura para a construção de sentidos que se atualizam em relação às problemáticas educacionais brasileiras ainda não superadas, especialmente, com o público jovem e adulto. A desestabilização do termo "contos" remete aos sentidos que extrapolam a letra ali expressa, escrita. É o que Authier-Revuz (2014) mostra com a ideia de "falta de captura do objeto pela letra", a "falha em nomear" (2014, p. 261). A representação pretendida pelos enunciadores ao elaborarem a campanha publicitária acaba por esvair-se e proporcionar a ultrapassagem do limite representado pela leitura dos "grandes contos brasileiros", pois há o infinito, o singular e a continuidade de sentidos. Deste modo, há a atualização do termo "contos" que passa a designar a realidade educacional e que marca o país: o analfabetismo e a baixa escolaridade. E é assim a construção dos sentidos:

[...] da não coincidência fundamental entre as duas ordens heterogêneas que a nomeação sobrepõe - ao que concerne ao geral, ao finito, ao discreto dos signos, e a que concerne ao singular, ao infinito, ao contínuo das 'coisas' -, do que se chamou a 'falta de captura do objeto pela letra', surge, no próprio princípio da nomeação, a dimensão de uma perda, de uma 'falha em nomear'. E é dessa falha em nomear - que, para o sujeito falante é particularmente falha para se nomear, falha para dizer a verdade que 'não se diz toda porque as palavras faltam' - que estruturalmente se constitui o sujeito, em um irredutível desvio de si mesmo, sujeito, pelo fato de que é falante e, por consequência do que ele é, falho. (AUTHIER-REVUZ, 2014, p. 261, grifos da autora)

É por meio do que é falho que há a atualização dos "grandes contos brasileiros", há a manifestação da possibilidade do vocábulo "contos" não representar somente a ficção, 
mas também, a realidade social do país. O sentido construído por meio da imagem se dá pela noção de formação discursiva, pois o sentido não está explícito nas palavras impressas na capa do livro que constitui uma significativa parte da imagem, muito menos na falsa objetividade de que o garoto não pode ler o livro que se encontra em suas mãos. Deste modo, "a formação discursiva se define como aquilo que numa formação ideológica dada - ou seja, a partir de uma posição dada em uma conjuntura sócio-histórica dada determina o que pode e deve ser dito" (ORLANDI, 2007a, p. 43).

Ainda em relação ao vocábulo "brasileiros", é relevante considerarmos as análises de Dias em relação ao vocábulo "brasileiro", pois há uma modalização,

[...] a palavra 'brasileiro' só pode ser pensada em relação à modalização, que imprime uma relação tensa entre a generalização (brasileiro $=$ aquele que nasce no Brasil) e a limitação (brasileiro $=$ aquele que satisfaz a um critério de verdade, de realidade). (DIAS, 1993, p. 87)

No caso de nossa sequência discursiva, trata-se de uma relevante indicação na capa do livro de contos, pois revela a opacidade dos contos que se relacionam à realidade, ou seja, uma tensão entre o garoto e os contos que é representada pelo fato do menino não saber ler. A inscrição "brasileiros" representa, justamente, os sujeitos que pertencem ao "critério de verdade, de realidade", são os brasileiros estigmatizados, privados do ato de ler, privados da educação libertadora. É como se os contos ignorassem o garoto, um leitor em potencial.

Conforme tais postulados, há a desestabilização do sentido representado pela imagem e que é construído por meio da estabilização de sentidos no imaginário dos sujeitos. O que ocorre é o rompimento com o estável, pois os baixos níveis de escolaridade ainda existentes no Brasil e que, por sua vez, atravessam a realidade de crianças e, consequentemente, de jovens e de adultos, constitui a representação dos "grandes contos brasileiros". Assim, a ruptura com o estável denega o sentido único estabelecido pela ficção literária e posteriores publicações de obras literárias ficcionais que muitas vezes estão publicadas e não podem ser lidas, mas passa a constituir uma realidade que perpassa a ficção e que a atualiza, ou seja, é o diálogo entre o ficcional e o real que passa a constituir os "grandes contos brasileiros" e inscreve a imagem na formação discursiva da exclusão.

\section{CONSIDERAÇÕES FINAIS}

Entendemos que a ideologia do governo perpassa o MEC e se manifesta nas Propostas Curriculares para a EJA, nos Cadernos e na Campanha Publicitária, e segundo esse movimento de sentidos, o governo acaba por eternizar a sua ideologia dominante perante a sociedade, perante os sujeitos e, consequentemente, em relação às políticas públicas educacionais. Nesse sentido, temos a presença da memória em relação ao discurso, ou seja, o interdiscurso. Assim, Orlandi (2007) mostra que a memória discursiva representa o saber discursivo que possibilita todo dizer e "retorna sob a forma do pré-construído, o já-dito que está na base do dizível, sustentando cada tomada da palavra" (p. 31). Em relação ao interdiscurso, inúmeros dizeres afetam a significação construída pelos sujeitos frente às diversas situações discursivas. 
Vimos que a imagem representada no recorte em estudo da Campanha Publicitária rompe com o estável já cristalizado no imaginário social e coloca em evidência o público jovem e adulto que não se escolarizou. Assim, representa essa infância denegada e marcada pela necessidade de trabalhar e romper com a escola. Essa realidade também denuncia os baixos níveis de escolaridade ainda existentes no Brasil e ultrapassa a ficção literária postulada pelos "grandes contos brasileiros", mas correlaciona a escolaridade desejável a um conto, ou seja, a uma obra ficcional. Essa mesma obra ficcional publicada também se situa para além daqueles que não podem lê-las, excluindo-os mais uma vez, emergindo com cada vez mais força a formação discursiva da exclusão.

\section{REFERÊNCIAS}

ACHARD, Pierre. Memória e produção discursiva do sentido. Em: ACHARD, Pierre et. al. Papel da memória. Tradução de José Horta Nunes. 2a . ed. Campinas: Pontes, 2007.

AUTHIER-REVUZ, Jacqueline. Falta do dizer, dizer da falta: as palavras do silêncio. Em: ORLANDI, E.P. Gestos de leitura: da história no discurso. $4^{\mathrm{a}}$. ed. Campinas: Ed. da Unicamp, 2014.

BRASIL. Ministério da Educação. Secretaria de Educação Continuada, Alfabetização e Diversidade. Trabalhando com a educação de jovens e adultos - Alunas e alunos de EJA. Cadernos EJA 1. Brasília: MEC/SECAD, 2006.

BRASIL. Ministério da Educação. Secretaria de Educação Fundamental. Educação de Jovens e Adultos: proposta curricular para o $1^{\circ}$ segmento do Ensino Fundamental. Brasília: Ação Educativa/MEC, 2001.

BRASIL. Campanha Publicitária: Educação de Jovens e Adultos. Disponível em https://www.youtube.com/watch?v=srIUUb4M7io. Acesso em 17/10/2016.

BRITTO, Luiz Percival Leme. A sombra do caos: ensino de língua x tradição gramatical. Campinas: Mercado de Letras, 2008.

DAVALLON, Jean. A imagem, uma arte de memória? Em: ACHARD, Pierre et. al. Papel da memória. Tradução de José Horta Nunes. $2^{\text {a }}$. ed. Campinas: Pontes, 2007.

MARIANI, B. Os primórdios da imprensa no Brasil (ou: de como o discurso jornalístico constrói memória). Em: ORLANDI, E.P. (Orga.). Materialidades discursivas. Campinas: Pontes, 1993. ORLANDI, E.P.; SOUZA, T.C.C. de. A língua imaginária e a língua fluida: dois métodos de trabalho com a linguagem. Em: ORLANDI, E.P. (Orga.). Política linguística na América Latina. Campinas: Pontes, 1988.

ORLANDI, E.P. Análise de Discurso: princípios e procedimentos. $7^{\mathrm{a}}$. ed. Campinas: Pontes, 2007.

PÊCHEUX, M. Abertura do Colóquio. Em: CONEIN, B. et. al. Materialidades discursivas. Trad. Bras. Campinas: Editora da Unicamp, 2016.

PÊCHEUX, M. Papel da memória. Em: ACHARD, Pierre et. al. Papel da memória. Tradução de José Horta Nunes. $2^{\text {a }}$. ed. Campinas: Pontes, 2007.

PÊCHEUX, M. Ideologia, interpelação, "Efeito Münchhausen". PÊCHEUX, M. Semântica e discurso: uma crítica à afirmação do óbvio. Trad. Bras. Campinas: Ed. da UNICAMP, 1988.

POSSENTI, Sírio. Teoria do discurso: um caso de múltiplas rupturas. Em: MUSSALIN, F.; BENTES, A.C. (Orgas.). Introdução à linguística: fundamentos epistemológicos. $5^{\mathrm{a}}$. ed. São Paulo: Cortez, 2011.

ROJO, Roxane. Modos de transposição dos $\mathrm{PCN}$ às práticas de sala de aula: progressão curricular e projetos. Em: ROJO, Roxane (Orga.). A prática de linguagem em sala de aula: praticando os PCN. Campinas: Mercado de Letras, 2006. 
Artigo recebido em: out. de 2019.

Aprovado e revisado em: nov. de 2019.

Publicado em: dezembro de 2019.

Para citar este texto:

TEIXEIRA, Odinei Inacio. Sobre a Educação de Jovens e Adultos - EJA: a educação e o trabalho para além da exclusão. Entremeios [Revista de Estudos do Discurso, ISSN 2179-3514, on-line, www.entremeios.inf.br], Seção Estudos, Programa de Pós-Graduação em Ciências da Linguagem (PPGCL), Universidade do Vale do Sapucaí (UNIVÁS), Pouso Alegre (MG), vol. 20, Especial, Dossiê "Língua, discurso e trabalho na contemporaneidade", p. 125-138, dez. 2019.

DOI: http://dx.doi.org/10.20337/ISSN2179-3514revistaENTREMEIOSvol20pagina125a138 